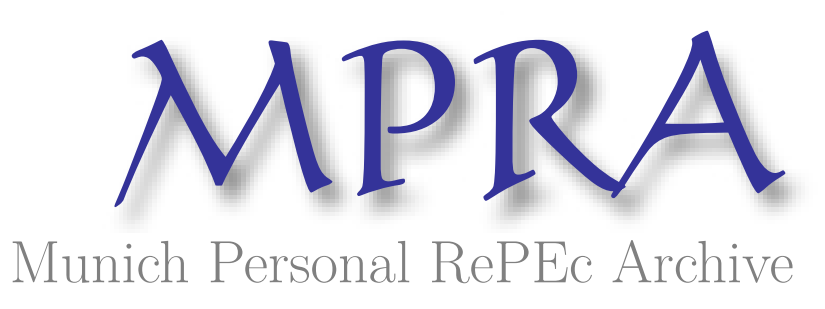

\title{
Analysis of within - month effects on the Bucharest stock exchange
}

Dumitriu, Ramona and Stefanescu, Razvan and Nistor, Costel

"Dunarea de Jos" University of Galati, "Dunarea de Jos" University of Galati, "Dunarea de Jos" University of Galati

11 August 2011

Online at https://mpra.ub.uni-muenchen.de/36562/

MPRA Paper No. 36562, posted 09 Feb 2012 23:09 UTC 


\title{
ANALYSIS OF WITHIN - MONTH EFFECTS ON THE BUCHAREST STOCK EXCHANGE
}

\author{
Lect, Ramona Dumitriu, Lect, Razvan Stefanescu, and Assoc Prof, Costel Nistor \\ “Dunarea de Jos” University, Galati, Romania, rdumitriu@ugal.ro
}

\begin{abstract}
This paper explores the presence of within - month effects on the Romanian capital markets. In our analysis we employ the daily values of some important indexes from two main components of the Bucharest Stock Exchange: BET, where there are listed some of the biggest Romanian corporations, and RASDAQ, which includes smaller companies. We find some significant differences between the calendar anomalies from the two markets. We also discover that in the last years within - month effects experienced some changes that could be linked with the development of the Romanian financial markets, by the adhesion to the European Union and by the global crisis.
\end{abstract}

Keywords: Calendar patterns, Romanian capital market, turn of the month effect, third month effect, half of the month effect

\section{JEL classification: G02, G01, G14,}

\section{Introduction}

In the last decades many scientific papers approached the within-month effects on the financial markets from various countries. Such calendar anomalies include the turn of the month, the third month and the half of the month effects.

Turn of the month (TOM) effect consists in significant differences between the stock returns from the so called TOM period which includes the first trading days of a month plus the last trading days from the precedent month and the stock returns from the so called rest of the month (ROM) period which includes the days not belonging to TOM period [1]. Third month effect is materialized in significant differences between the stock returns from three periods associated to a month: first period $\left(\mathrm{TM}_{1}\right)$ from $28^{\text {th }}$ of the previous month to $7^{\text {th }}$ of the current month, second period $\left(\mathrm{TM}_{2}\right)$ from $8^{\text {th }}$ to $17^{\text {th }}$ of the current month and the third period $\left(\mathrm{TM}_{3}\right)$ from $18^{\text {th }}$ to $27^{\text {th }}$ of the current month [2]. Half of the month effect consists in the tendency of stock returns to be higher in the first half of a month in comparison with the second half [3].
In this paper we study the withinmonth effects on the Bucharest Stock Exchange (BSE). In the last years BSE experienced some significant transformations. It was reopened in 1995 after its activity had been suspended for decades by the communist regime. In the first years, due to the slowly privatisation and the barriers to the foreign capitals, the volume of transactions remained to low levels. The effects of the East Asian Crisis and some difficulties of the transition led to a decline of the stock prices on the late 1990s. At the beginning of the 2000s the government measure to accelerate privatisation and to attract foreign capitals stimulated the recovery of BSE. After Romania's adhesion to the European Union, in January 2007, BSE became more attractive for the foreign investors. However, in the second half of 2008 the global crisis caused another decline in stock prices. Since 2009, BSE recovered partially from the loss caused by the contagion from the foreign markets.

We analyze the within-month effect from two main components of BSE: BET and RASDAQ. On BET market there are 
listed the biggest Romanian companies, while RASDAQ market includes, in general, rather smaller companies. We use daily values of two main indexes: BET-C for BET market and RAQ-C for RASDAQ market (Figure 1). We try to identify the calendar anomalies employing regressions with dummy variables for two periods of time: first from January 2002 to December 2006 and second from January 2007 to June 2011.

The rest of this paper is organized as follows. The second part approaches the relevant literature, the third part describes the data and methodology used in our investigation, the fourth part presents the empirical results, while the fifth part concludes.

\section{Literature Review}

Some hypotheses were formulated to explain the within-month effects. Pay Day Hypothesis considers that usually at the end of a month many investors need cash money for paying the dividends, the interests or even the wages of their employees. They withdraw that money from the market, reinvesting it at the beginning of the new month [4]. Window Dressing Hypothesis explains the TOM effect by the tendency of some investors to keep in their portfolios, at the end of a month, where their performances are analyzed, only stocks with high returns, in order to show favourable results. As the new month starts they will buy back the stocks they sold [5]. Earning Announcement Hypothesis is based on the impact of the announcements about the results of a firm on its stock returns. Most of these announcements are made in the last days of the month, leading to significant changes [6].

Calendar anomalies were used as arguments to invalidate the Efficient Market Hypothesis (EMH) which states that past values of stock prices couldn't be used to predict future values [7]. However, the defenders of EMH consider that after they became public, most of the stock market anomalies disappear or they go into reverse because their exploitation by an increasing number of investors [8]. The rational behaviour of the investor could cause a life cycle for any calendar anomaly [9]. Sometimes significant events, such a financial crisis, could provoke considerable changes in the calendar anomalies [10].

Many studies approached the particularities of calendar patterns on the emerging markets, explaining them by some characteristics of the financial markets' development stages [11]. There were also revealed some differences between the calendar anomalies from big corporation stocks in comparison with smaller firms. Such differences were explained by the firm size impact on the investors' behaviour [12].

\section{Data and Methodology}

In our analysis we employ daily values of BET-C and RAQ-C, provided by $\mathrm{BSE}$, for the period from $3^{\text {rd }}$ January 2002 to $30^{\text {th }}$ June 2011 . We divide this period of time in two parts:

- first sub-sample, from $3^{\text {rd }}$ January 2002 to $19^{\text {th }}$ December 2006, corresponding to a period of almost continuous development of the capital market in Romania;

- second sub-sample, from $3^{\text {rd }}$ January 2007 to $30^{\text {th }}$ June 2011 when the effects of Romania's adhesion to the European Union and of the global crisis caused significant changes on the financial markets.

For both indexes we calculate the returns using the formula:

$$
\mathrm{R}_{\mathrm{t}}=100 *\left[\ln \left(\mathrm{P}_{\mathrm{t}}\right)-\ln \left(\mathrm{P}_{\mathrm{t}-1}\right)\right]
$$

where $P_{t}$ is the values of an index at day $t$.

In order to reveal the within-month effects we employ regressions with dummy variables. We use the Ljung - Box test to identify possible autocorrelation in the residuals of each regression. If this test indicates the presence of autocorrelation in a regression we introduce AR-terms choosing the number of lags based on the Akaike Information criterion. We also employ the LM test to detect possible conditional heteroskedasticity in the error terms. In such situation, the regression is 
corrected with GARCH-terms.

We investigate TOM effect using the regression:

$$
R_{t}=\sum_{i=-6}^{6} \alpha_{i} \text { TOM }_{i, t}+\beta_{0} R O M_{t}+\varepsilon_{t}
$$

where $R_{t}$ is the return of BET-C or RAQ-C on day $t, i$ refers to the trading day of TOM period, $\mathrm{TOM}_{\mathrm{i}, \mathrm{t}}$ is a dummy variable corresponding to day $i$, taking the value 1 on day $\mathrm{i}$ and zero otherwise, $\mathrm{ROM}_{t}$ is another dummy variable taking the value 1 on the ROM period and zero otherwise, $\alpha_{i}$ and $\beta_{0}$ are coefficients of regression, $\varepsilon_{t}$ is the error term.

We test the third month effect by employing the regression:

$$
\mathrm{R}_{\mathrm{t}}=\gamma_{0}+\gamma_{2} \mathrm{TM}_{2}+\gamma_{3} \mathrm{TM}_{3}+v_{\mathrm{t}}
$$

where $\mathrm{TM}_{2}$ is a dummy variable taking the value 1 in the $\mathrm{TM}_{2}$ period and zero otherwise, $\mathrm{TM}_{3}$ is a dummy variable taking the value 1 on the $\mathrm{TM}_{3}$ period and zero otherwise, $\gamma_{0}, \gamma_{2}$ and $\gamma_{3}$ are coefficients of regression, $v_{\mathrm{t}}$ is the error term.

Finally, we investigate half of the month effect using the regression:

$$
\mathrm{R}_{\mathrm{t}}=\delta_{0}+\delta_{1} \mathrm{HM}_{2}+\eta_{\mathrm{t}}
$$

where $\mathrm{HM}_{2}$ is a dummy variable taking the value 1 on the second half of a month and zero otherwise, $\delta_{0}$ and $\delta_{1}$ are coefficients of regression, $\eta_{\mathrm{t}}$ is the error term.

\section{Empirical Results}

The Table 1 shows the results of the equation (2) for BET-C index. They reveal a TOM effect for the first sub-sample concentrated in the window [-1 to 3]. For the second sub-sample the significant trading days are dispersed. In the Table 2 there are presented the results of the same equation for RAQ-C index. The significant trading days are dispersed for both subsamples.

We tested the third month effect using the equation (3). For BET-C index, the results show a significant value for all variables in case of the second sub-sample and only for intercept in case of first subsample (Table 3). For RAQ-C index we found no evidence of the third month effect (Table 4).

In the Table 5 there are presented the results of the equation (4) for BET-C index. They indicate a significant value of intercept for the first sub-sample and no half of the month effect for the second subsample. For RAQ-C index we found significant value of intercept in case of the first sub-sample and of $\mathrm{HM}_{2}$ in case of the second sub-sample (Table 6).

\section{Conclusions}

In this paper we investigated the within-month effects on the BSE. We found that significant changes occurred after the Romania's adhesion to European Union. Before the adhesion, BET market exhibited a quit consistent TOM and half of the month effects which almost disappeared after the adhesion. We could link these evolutions with the turbulences generated by the massive inflows of the foreign capitals that occurred immediately after the adhesion and with the impact of the global crisis. On the RASDAQ market, we found no evidence of a TOM effect before or after the adhesion while the half of the month effect experienced some significant changes.

The third month effect on BET market seems to be more consistent after the adhesion than before. We could explain this change with the fact that after the adhesion and especially during the crisis, the investors became more sensitive to the macroeconomic news provided with regularity in certain periods of a month. We found no third month effect on RASDAQ market before or after the adhesion.

The significant differences between the two main components of BSE could be explained by their characteristics. On BET market the foreign investors play a major role while RASDAQ market is not very attractive for them. 


\section{References}

[1] Lakonishok. J. and S. Smidt, Are Seasonal Anomalies Real? A Ninety Years Perspective, Review of Financial Studies, 1(4): pp. 403-425, 1988.

[2] Kohers T. and J.B. Patel, A New Time of the Month Anomaly in Stock Index Returns, Applied Economics Letters, 6(2), pp. 115-120, 1999.

[3] Ariel R. A., A Monthly Effect in Stock Returns, Journal of Financial Economics, 18, pp. 161-74, 1987.

[4] Fatta Bahadur K.C., Navan K. J., The Nepalese Stock Market: Efficiency and Calendar Anomalies, Economic Review, Vol. 17, No. 17, 2005.

[5] Lakonishok J., Schleifer A., Thaler R., Vishny R., Window Dressing by Pension Fund Managers, The American Economic Review, 82, pp. 227-232, 1991.

[6] Peterson D.R., Stock return seasonalities and earnings information, Journal of Quantitative Analysis, 25, pp. 74-86, 1990.

[7] Fama Eugene, Market Efficiency, Long-Term Returns and Behavioural Finance, Journal of Financial Economics, 49, pp. 283-306, 1998.

[8] Dimson E. and P. Marsh, Murphy's Law and Market Anomalies, Journal of Portfolio Management 25(2) pp. 53-69, 1999.

[9] Steeley J.M., A Note on Information Seasonality and the Disappearance of the Weekend Effect in the UK Stock Market, Journal of Banking and Finance 25(10), pp. 1941-1956, 2001.

[10] Blackman S.C., Holden K. and Thomas W.A., Long-term relationships between international share prices, Applied Financial Economics, 4, pp. 297-304, 1994.

[11] Maghayereh A., Seasonality and January Effect Anomalies in an Emerging Capital Market, The Arab Bank Review, 5(2), pp. 25-32, 2003.

[12] Keim D., Size Related Anomalies and Stock Market Seasonality; Further Empirical Evidence, Journal of Financial Economics, 12: pp. 12-32, 1983.

\section{Appendix}

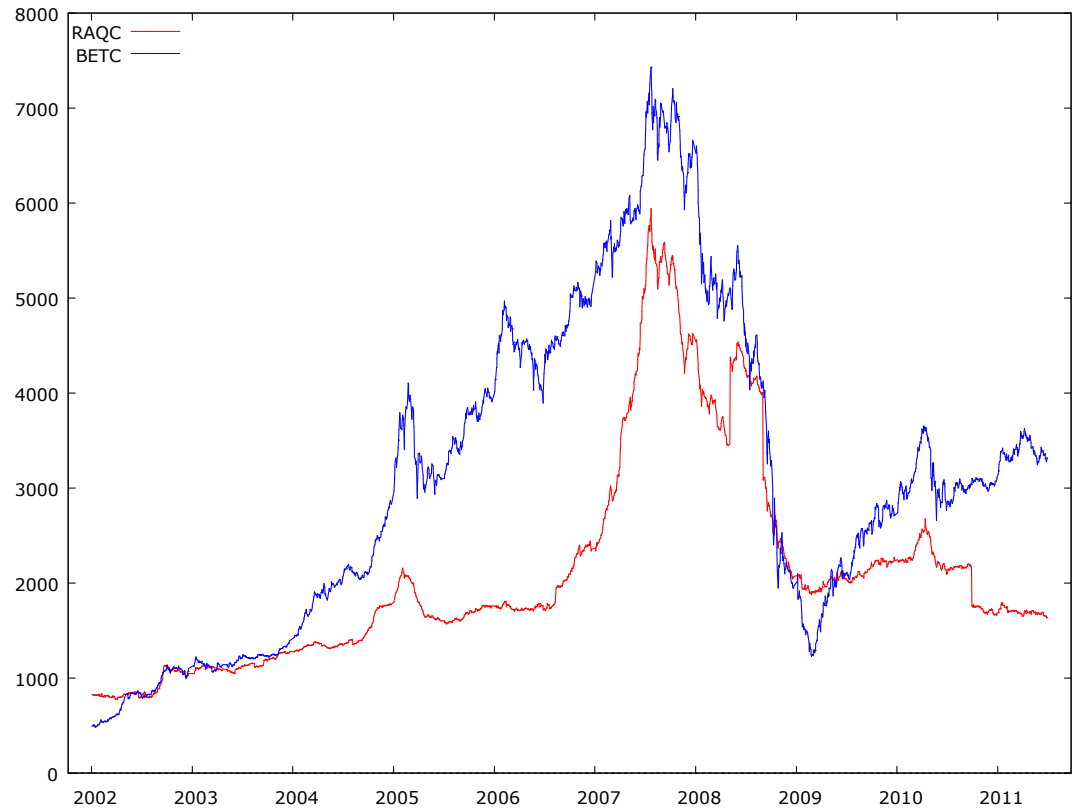

Figure 1: Evolution of BET-C and RAQ-C from January 2002 to June 2011 
Table 1 Turn of the month effect for BET-C returns

\begin{tabular}{|l|l|l|l|l|l|l|}
\hline \multirow{2}{*}{ Variable } & \multicolumn{3}{|c}{ First sub-sample } & \multicolumn{3}{c|}{ Second sub-sample } \\
\cline { 2 - 7 } & Coefficient & \multicolumn{1}{|c|}{ z-stat } & \multicolumn{1}{c|}{-value } & \multicolumn{1}{c|}{ Coefficient } & z-stat & -value \\
\hline TOM $_{-6}$ & -0.0341947 & -0.2839 & 0.77649 & -0.0949946 & -0.5457 & 0.58527 \\
\hline TOM $_{-5}$ & 0.0351562 & 0.2918 & 0.77043 & 0.319843 & 1.8896 & 0.05881 \\
\hline TOM $_{-4}$ & 0.0416088 & 0.3410 & 0.73308 & -0.166796 & -1.0228 & 0.30638 \\
\hline TOM $_{-3}$ & 0.0657308 & 0.5258 & 0.59899 & -0.145282 & -0.8382 & 0.40190 \\
\hline TOM $_{-2}$ & 0.0671761 & 0.5356 & 0.59226 & 0.281708 & 1.6345 & 0.10215 \\
\hline TOM $_{-1}$ & $\mathbf{0 . 2 8 0 1 3 8}$ & $\mathbf{2 . 2 1 9 0}$ & $\mathbf{0 . 0 2 6 4 9}$ & 0.172971 & 0.9905 & 0.32194 \\
\hline TOM $_{1}$ & $\mathbf{0 . 5 4 3 2 4 2}$ & $\mathbf{4 . 7 8 2 8}$ & $<\mathbf{0 . 0 0 0 0 1}$ & 0.376913 & 2.2180 & 0.02655 \\
\hline TOM $_{2}$ & $\mathbf{0 . 2 3 2 8 7 2}$ & $\mathbf{1 . 8 6 2 8}$ & $\mathbf{0 . 0 6 2 4 9}$ & 0.161607 & 0.9955 & 0.31952 \\
\hline TOM $_{3}$ & $\mathbf{0 . 2 3 7 5 8}$ & $\mathbf{1 . 9 1 2 8}$ & $\mathbf{0 . 0 5 5 7 7}$ & -0.05868 & -0.3184 & 0.75020 \\
\hline TOM $_{4}$ & 0.159311 & 1.2453 & 0.21304 & 0.285392 & 1.6920 & 0.09064 \\
\hline TOM $_{5}$ & 0.012084 & 0.0999 & 0.92042 & 0.214684 & 1.2741 & 0.20262 \\
\hline TOM $_{6}$ & 0.0267598 & 0.2164 & 0.82865 & -0.194886 & -1.1316 & 0.25782 \\
\hline ROM & $\mathbf{0 . 2 1 5 3 3 2}$ & $\mathbf{3 . 1 1 2 0}$ & $\mathbf{0 . 0 0 1 8 6}$ & 0.108804 & 1.0800 & 0.28014 \\
\hline ARCH$(0)$ & $\mathbf{0 . 0 7 1 9 3 0 8}$ & $\mathbf{3 . 2 7 8 7}$ & $\mathbf{0 . 0 0 1 0 4}$ & $\mathbf{0 . 0 6 8 1 3 5 1}$ & $\mathbf{2 . 4 0 3 5}$ & $\mathbf{0 . 0 1 6 2 4}$ \\
\hline ARCH $(1)$ & $\mathbf{0 . 2 1 2 8 5 7}$ & $\mathbf{6 . 0 1 0 9}$ & $<\mathbf{0 . 0 0 0 0 1}$ & $\mathbf{0 . 2 0 7 2 9 3}$ & $\mathbf{5 . 7 3 8 5}$ & $<\mathbf{0 . 0 0 0 0 1}$ \\
\hline GARCH(1) & $\mathbf{0 . 7 6 0 4 6 2}$ & $\mathbf{2 0 . 3 4 9 8}$ & $<\mathbf{0 . 0 0 0 0 1}$ & $\mathbf{0 . 7 9 2 7 0 7}$ & $\mathbf{2 3 . 0 8 5 1}$ & $<\mathbf{0 . 0 0 0 0 1}$ \\
\hline
\end{tabular}

Note: Estimates that are significant at 5\% (10\%) level are in bold face (italics).

Table 2 Turn of the month effect for $R A Q-C$ returns

\begin{tabular}{|c|c|c|c|c|c|c|}
\hline \multirow[t]{2}{*}{ Variable } & \multicolumn{3}{|c|}{ First sub-sample } & \multicolumn{3}{|c|}{ Second sub-sample } \\
\hline & Coefficient & $z$-stat & $p$-value & Coefficient & $z$-stat & $p$-value \\
\hline $\mathrm{TOM}_{-6}$ & -0.0134082 & -0.1537 & 0.87787 & -0.0386116 & -0.2539 & 0.7995 \\
\hline TOM $_{-5}$ & 0.097134 & 1.1176 & 0.26373 & -0.251567 & -1.416 & 0.1568 \\
\hline $\mathrm{TOM}_{-4}$ & -0.0213434 & -0.2406 & 0.80988 & -0.144226 & -1.060 & 0.2892 \\
\hline $\mathrm{TOM}_{-3}$ & -0.0330322 & -0.3727 & 0.70937 & 0.0673465 & 0.4650 & 0.6419 \\
\hline $\mathrm{TOM}_{-2}$ & -0.0350621 & -0.3961 & 0.69199 & 7.20220 & 1.002 & 0.3162 \\
\hline TOM $_{-1}$ & 0.120546 & 1.3414 & 0.17980 & -3.48545 & -0.8637 & 0.3877 \\
\hline $\mathrm{TOM}_{1}$ & -0.0278464 & -0.3103 & 0.75630 & -0.434263 & -2.017 & 0.0437 \\
\hline $\mathrm{TOM}_{2}$ & 0.186104 & 2.0968 & 0.03601 & 24.0351 & 1.504 & 0.1325 \\
\hline $\mathrm{TOM}_{3}$ & 0.129195 & 1.4370 & 0.15072 & -12.9631 & -1.442 & 0.1493 \\
\hline $\mathrm{TOM}_{4}$ & 0.126305 & 1.4265 & 0.15372 & 0.0698764 & 0.2690 & 0.7879 \\
\hline $\mathrm{TOM}_{5}$ & -0.14819 & -1.6921 & 0.09064 & -0.141530 & -0.3631 & 0.7165 \\
\hline $\mathrm{TOM}_{6}$ & 0.0458312 & 0.5090 & 0.61075 & 0.241621 & 1.643 & 0.1003 \\
\hline ROM & 0.04739 & 0.9214 & 0.35683 & -0.0759672 & -0.6108 & 0.5413 \\
\hline $\mathrm{ARCH}(0)$ & $\begin{array}{l}0.0030863 \\
\end{array}$ & 2.7894 & 0.00528 & 0.227997 & 2.782 & 0.0054 \\
\hline ARCH(1) & 0.0249036 & 5.4865 & $<0.0001$ & 0.241859 & 3.332 & 0.0009 \\
\hline GARCH(1) & 0.972465 & 230.2204 & $<0.0001$ & 0.545444 & 5.889 & $<0.00001$ \\
\hline
\end{tabular}

Note: Estimates that are significant at 5\% (10\%) level are in bold face (italics).

Table 3 Third month effect for BET-C returns

\begin{tabular}{|l|l|l|c|c|c|c|}
\hline \multirow{2}{*}{ Variable } & \multicolumn{3}{|c}{ First sub-sample } & \multicolumn{3}{c|}{ Second sub-sample } \\
\cline { 2 - 7 } & Coefficient & z-stat & p-value & Coefficient & $z$-stat & p-value \\
\hline const & $\mathbf{0 . 1 6 7 1 1 4}$ & $\mathbf{3 . 4 3 0 9}$ & $\mathbf{0 . 0 0 0 6 0}$ & $\mathbf{0 . 1 9 9 7 6 5}$ & $\mathbf{2 . 9 2 2 6}$ & $\mathbf{0 . 0 0 3 4 7}$ \\
\hline $\mathrm{TM}_{2}$ & 0.0337949 & 0.5011 & 0.61629 & $\mathbf{- 0 . 2 2 2 4 2 6}$ & $\mathbf{- 2 . 3 6 6 9}$ & $\mathbf{0 . 0 1 7 9 4}$ \\
\hline
\end{tabular}




\begin{tabular}{|l|l|l|l|l|l|l|}
\hline $\mathrm{TM}_{3}$ & -0.0232157 & -0.3312 & 0.74049 & $\mathbf{- 0 . 2 1 3 0 2 6}$ & $\mathbf{- 2 . 2 3 6 7}$ & $\mathbf{0 . 0 2 5 3 0}$ \\
\hline ARCH $(0)$ & $\mathbf{0 . 0 6 7 4 9 1 9}$ & $\mathbf{3 . 1 0 1 4}$ & $\mathbf{0 . 0 0 1 9 3}$ & $\mathbf{0 . 0 7 7 0 9 0 9}$ & $\mathbf{2 . 6 0 4 1}$ & $\mathbf{0 . 0 0 9 2 1}$ \\
\hline ARCH $(1)$ & $\mathbf{0 . 2 1 2 6 7 8}$ & $\mathbf{5 . 8 5 7 4}$ & $<\mathbf{0 . 0 0 0 0 1}$ & $\mathbf{0 . 2 1 3 2 4 6}$ & $\mathbf{5 . 8 3 1 2}$ & $<\mathbf{0 . 0 0 0 1}$ \\
\hline GARCH $(1)$ & $\mathbf{0 . 7 6 5 3 8 5}$ & $\mathbf{2 0 . 2 1 1 6}$ & $<\mathbf{0 . 0 0 0 0 1}$ & $\mathbf{0 . 7 8 6 7 5 4}$ & $\mathbf{2 3 . 3 0 5 4}$ & $<\mathbf{0 . 0 0 0 1}$ \\
\hline
\end{tabular}

Note: Estimates that are significant at 5\% (10\%) level are in bold face (italics).

\begin{tabular}{|c|c|c|c|c|c|c|}
\hline \multirow{3}{*}{ Variable } & \multirow{2}{*}{\multicolumn{3}{|c|}{ First sub-sample }} & 4 Third & $c t j$ & - $-C r e$ \\
\hline & & & & \multicolumn{3}{|c|}{ Second sub-sample } \\
\hline & Coefficient & $z$-stat & $p$-value & Coefficient & $z$-stat & $p$-value \\
\hline const & 0.0364621 & 1.0515 & 0.29304 & 0.106567 & 0.9577 & 0.3382 \\
\hline $\mathrm{TM}_{2}$ & 0.0236306 & 0.4933 & 0.62181 & -0.171232 & -1.392 & 0.1638 \\
\hline $\mathrm{TM}_{3}$ & 0.063198 & 1.3027 & 0.19269 & -0.166945 & -1.390 & 0.1645 \\
\hline $\mathrm{ARCH}(0)$ & 0.00312997 & 2.8845 & 0.00392 & 4.01048 & 1.268 & 0.2049 \\
\hline $\mathrm{ARCH}(1)$ & 0.0241708 & 5.5358 & $<0.0001$ & 0.317170 & 2.857 & 0.0043 \\
\hline GARCH(1) & 0.973026 & 234.85 & $<0.0001$ & 0.204662 & 0.6646 & 0.5063 \\
\hline
\end{tabular}

Note: Estimates that are significant at 5\% (10\%) level are in bold face (italics).

Table 5 Half of the month effect for BET-C returns

\begin{tabular}{|l|l|l|l|l|l|c|}
\hline \multirow{2}{*}{ Variable } & \multicolumn{3}{|c}{ First sub-sample } & \multicolumn{3}{c|}{ Second sub-sample } \\
\cline { 2 - 7 } & \multicolumn{1}{|c|}{ Coefficient } & \multicolumn{1}{|c}{ z-stat } & p-value & \multicolumn{1}{c|}{ Coefficient } & z-stat & $p$-value \\
\hline const & 0.20118 & 5.0659 & $<0.00001$ & 0.071473 & 1.2813 & 0.20009 \\
\hline $\mathrm{HM}_{2}$ & -0.0594924 & -1.0604 & 0.28895 & -0.0397563 & -0.5202 & 0.60295 \\
\hline $\mathrm{ARCH}(0)$ & $\mathbf{0 . 0 6 6 1 7 8 2}$ & $\mathbf{3 . 0 8 3 8}$ & $\mathbf{0 . 0 0 2 0 4}$ & $\mathbf{0 . 0 7 6 0 2 8 1}$ & $\mathbf{2 . 6 1 0 5}$ & $\mathbf{0 . 0 0 9 0 4}$ \\
\hline $\mathrm{ARCH}(1)$ & $\mathbf{0 . 2 1 0 1 6 8}$ & $\mathbf{5 . 8 6 1 7}$ & $<\mathbf{0 . 0 0 0 0 1}$ & $\mathbf{0 . 2 0 8 9 6 2}$ & $\mathbf{5 . 6 7 2 9}$ & $<\mathbf{0 . 0 0 0 0 1}$ \\
\hline $\mathrm{GARCH}(1)$ & $\mathbf{0 . 7 6 8 1 8 7}$ & $\mathbf{2 0 . 5 0 3}$ & $<\mathbf{0 . 0 0 0 0 1}$ & $\mathbf{0 . 7 9 0 4 4 5}$ & $\mathbf{2 3 . 1 9 2 2}$ & $<\mathbf{0 . 0 0 0 0 1}$ \\
\hline
\end{tabular}

Note: Estimates that are significant at $5 \%(10 \%)$ level are in bold face (italics).

Table 6 Half of the month effect for $R A Q-C$ returns

\begin{tabular}{|l|l|l|l|l|l|l|}
\hline \multirow{2}{*}{ Variable } & \multicolumn{3}{|c|}{ First sub-sample } & \multicolumn{3}{c|}{ Second sub-sample } \\
\cline { 2 - 7 } & \multicolumn{1}{|c|}{ Coefficient } & \multicolumn{1}{|c|}{ z-stat } & p-value & Coefficient & $z$-stat & $p$-value \\
\hline const & $\mathbf{0 . 0 5 6 9 9 2 1}$ & $\mathbf{2 . 0 3 5 3}$ & $\mathbf{0 . 0 4 1 8 2}$ & 0.0505017 & 0.7385 & 0.4602 \\
\hline $\mathrm{HM}_{2}$ & 0.0166612 & 0.4248 & 0.67098 & -0.141067 & -1.830 & 0.0672 \\
\hline $\mathrm{ARCH}(0)$ & $\mathbf{0 . 0 0 3 1 6 5 0 9}$ & $\mathbf{2 . 8 8 3 9}$ & $\mathbf{0 . 0 0 3 9 3}$ & $\mathbf{- 0 . 2 2 4 8 6 6}$ & $\mathbf{- 2 . 8 4 1}$ & $\mathbf{0 . 0 0 4 5}$ \\
\hline $\mathrm{ARCH}(1)$ & $\mathbf{0 . 0 2 3 8 5 4 2}$ & $\mathbf{5 . 5 1 0 1}$ & $<\mathbf{0 . 0 0 0 0 1}$ & $\mathbf{0 . 2 0 9 3 7 4}$ & $\mathbf{2 . 6 2 3}$ & $\mathbf{0 . 0 0 8 7}$ \\
\hline $\mathrm{GARCH}(1)$ & $\mathbf{0 . 9 7 3 2 2 1}$ & $\mathbf{2 3 5 . 4 5 1 3}$ & $<\mathbf{0 . 0 0 0 0 1}$ & $\mathbf{0 . 9 7 9 1 6 8}$ & $\mathbf{5 3 . 3 3}$ & $\mathbf{0 . 0 0 0 1}$ \\
\hline
\end{tabular}

Note: Estimates that are significant at 5\% (10\%) level are in bold face (italics). 